\title{
Robert's uterus: a rare mullerian anomaly mystery unfolded
}

\section{T. Ramani Devi ${ }^{1 *}$, C. Archana Devi ${ }^{2}$}

\author{
${ }^{1}$ Department of Obstetrics and Gynecology, Ramakrishna Medical Centre LLP and Janani Fertility Centre, Trichy, \\ Tamil Nadu, India \\ ${ }^{2}$ Department of Obstetrics and Gynecology, Ramakrishna Medical Centre LLP, Trichy, Tamil Nadu, India
}

Received: 22 April 2020

Accepted: 29 May 2020

\author{
*Correspondence: \\ Dr. T. Ramani Devi, \\ E-mail: ramanidevi@gmail.com
}

Copyright: (c) the author(s), publisher and licensee Medip Academy. This is an open-access article distributed under the terms of the Creative Commons Attribution Non-Commercial License, which permits unrestricted non-commercial use, distribution, and reproduction in any medium, provided the original work is properly cited.

\begin{abstract}
Anomalies of female genital tract may not be detected until after menarche when they present a cyclical pain due to outlet obstruction. Mullerian anomalies represent a vast array of structural abnormalities resulting from improper development and fusion of embryological mullerian ducts. 19-year-old girl attained menarche at the age of 14, had progressive dysmenorrhoea and diagnosed as right haemotosalphinx and ovarian endometrioma which were removed in 2008. As pain progressed, she underwent laparoscopic adhesiolysis in 2013. Since, pain persisted, diagnosed as right haematometra, and drainage done by laparotomy. Left adnexa were normal. She was given depot provera till she completed schooling. She developed recurrent dysmenorrhoea after stopping depot provera. USG and MRI revealed recurrent haematometra on right side with normal left horn. The possibility of atypical septum was thought about and hystero laparoscopy was done. It showed right side haemetometra with absent right adnexa. Left adnexa normal. Hysteroscopy showed normal left horn with septum with a bulge towards the left side. Hence, proceeded with hysteroscopic septostomy and haemetometra was drained to the left horn. Later patient was free from dysmenorrhea and repeat hysteroscopy was found to be normal. This case highlighting mullerian anomalies have to be considered when young girls present with severe progressive dysmenorrhoea and diagnosis remains a challenge most of the clinicians. This rare entity has to be kept in mind while evaluating such patients. Prompt diagnosis and early surgical correction are essential to avoid future morbidity in the form of repeated unnecessary surgeries.
\end{abstract}

Keywords: Dysmenorrhea, Failure to diagnose leads to repeated surgeries, Mullerian anomaly, Roberts uterus, Septate uterus, Variant of class V ASRM classification of mullerian anomaly

\section{INTRODUCTION}

Mullerian anomalies are rare and fascinating. The incidence being $0.1-3.5 \%$ among general population and there is increased incidence among recurrent aborters up to $5-10 \%{ }^{1}$ These patients present with progressive dysmenorrhoea. Mullerian anomalies are associated with renal anomalies in $30 \%$ of the cases. If diagnosis is not made in the earlier stage, it will lead to repeated unnecessary surgeries. These anomalies are also associated with repeated reproductive failure. Here, authors are presenting a case of Robert's uterus, a rare type of uterine anomaly, where there is asymmetric obstructed lateral fusion defect. This patient had undergone multiple surgeries before the correct diagnosis was made. American fertility society (AFS) classification of mullerian anomaly does not describe this anomaly. Septate uterus belonging to AFS class V is the commonest anomaly and septum is usually partial or complete. Atypical septum is usually very rare and this is named as Robert's uterus. ESHRE/ESGE classification explains this anomaly as U2U6C0V0.

\section{CASE REPORT}

Miss. M, 19-year-old attained menarche at the age of 14 years. Menstruation was uneventful for 1 year. Then she developed dysmenorrhea which was progressive in 
nature. Her cycles were regular. She was diagnosed to have right ovarian cyst and haemato salphinx for which she underwent right salphingo oophorectomy in the year 2008 through laparotomy. The ovarian mass was diagnosed as endometrioma. Her pain did not subside and dysmenorrhea continued even after the surgery. Again in 2013, she underwent laparoscopy and adhesiolysis. Pain persisted and she consulted a gynecologist, who suggested USG which showed hypo echoic mass in the right side of the uterus. Probable diagnosis of right endometrioma or haematometra was made. She was posted for third surgery. Laparotomy was done, where right side of the uterus had haematometra which was drained by an incision over the right side cornual region. Right ovary and tube were absent and left side tube and ovary were normal. She was started on depot provera which kept her amenorrhoeic till she completed her school studies. Then she stopped depot provera. After 3 months she regained her menstrual cycle with severe dysmenorrhea. With this history she reached us.

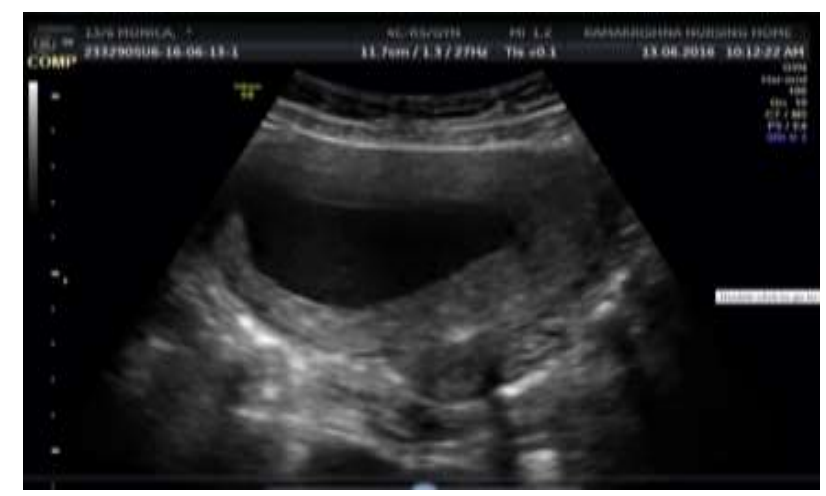

Figure 1: USG of right side hematometra and left horn of the uterus with the patent vagina.

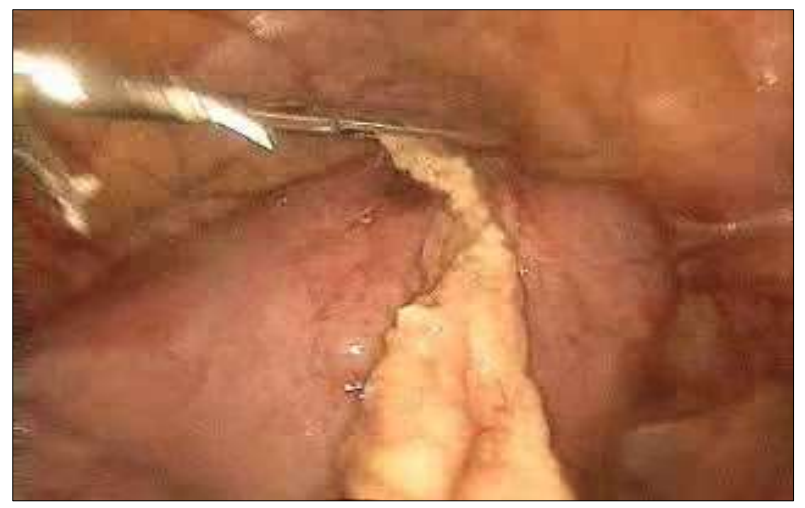

Figure 2: Laparoscopic view.

Her general condition and general examination were normal. Abdominal examination revealed only lower abdominal tenderness and no mass was felt. She had already done MRI outside, which showed a hypo-echoic mass in the right side of the uterus. Left horn of the uterus was normal communicating with the vagina. Right ovary was absent. Left ovary was normal. Both kidneys were normal.

Ultra-sonography done at study centre also revealed a haematometra on right horn, which compressed the left horn of the uterus and a patent vagina (Figure 1). Left ovary was normal and right ovary could not be imaged. Screening of the abdomen was normal.

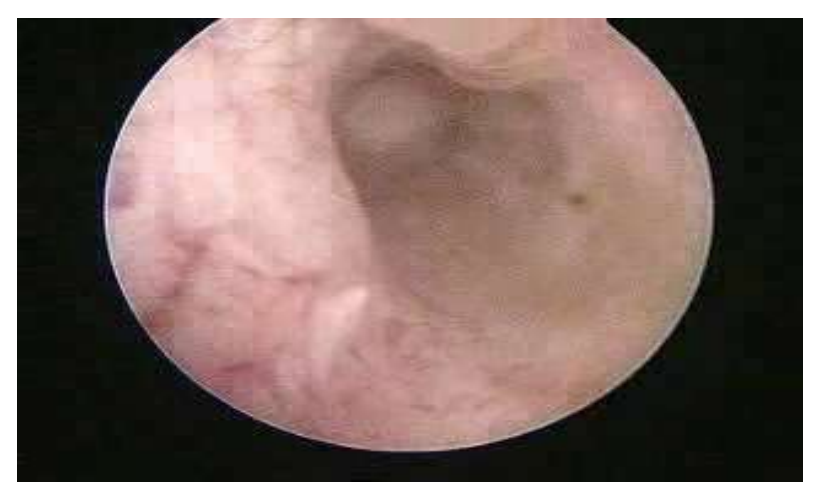

Figure 3: Hysteroscopic view.

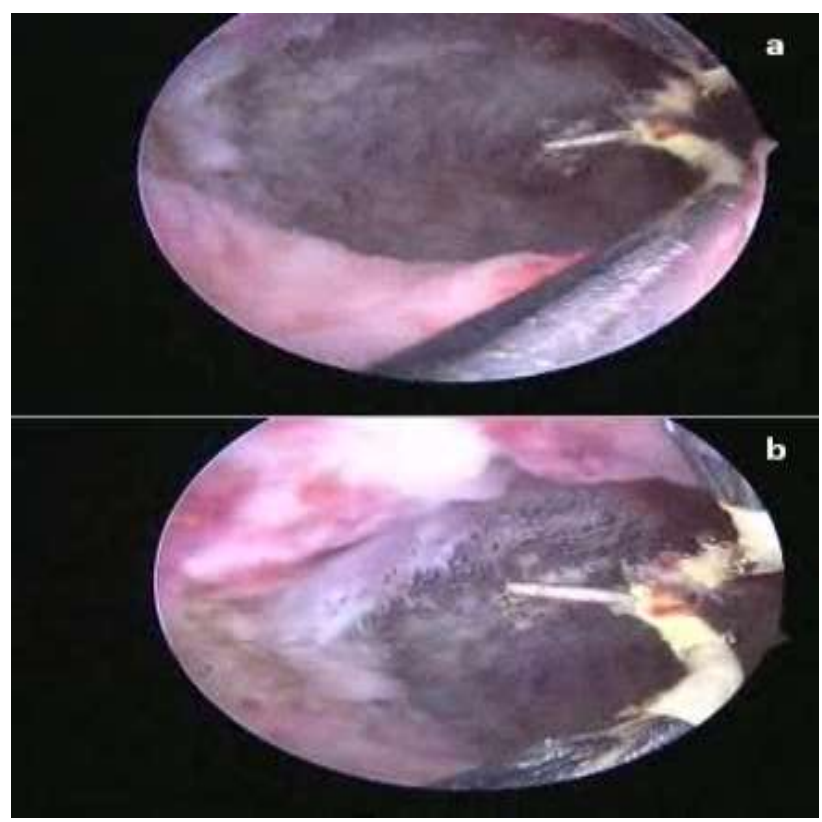

Figure 4: (a, b) Hysteroscopic resection.

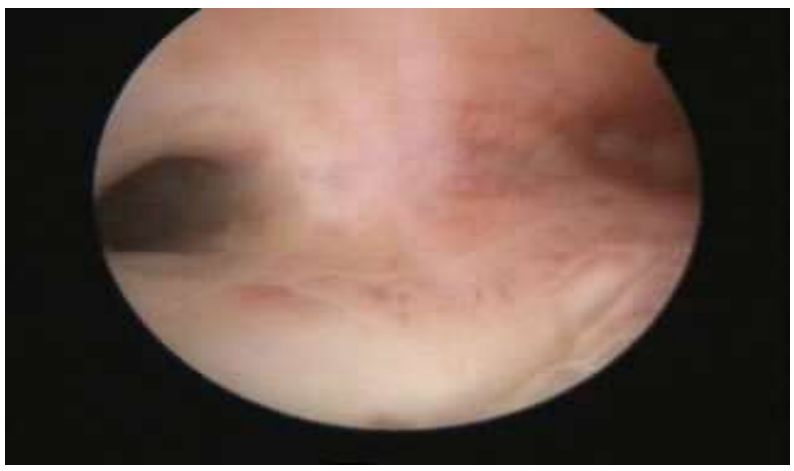

Figure 5: Relook hysterscopic view. 


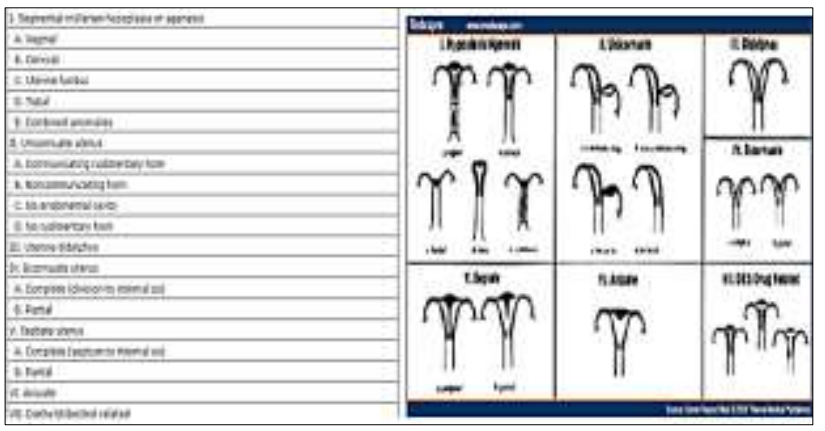

Figure 6: AFS classification.

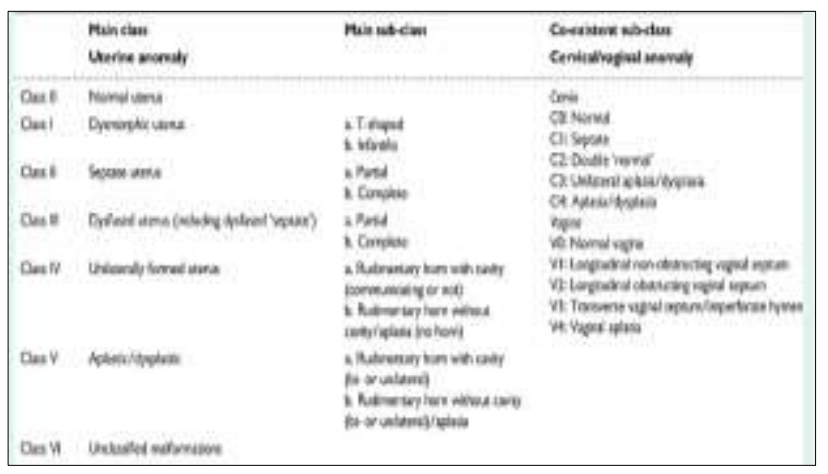

Figure 7: ESHRE/ESGE classification.

Hence, a provisional diagnosis of Robert's uterus was made. She was planned for hystero laparoscopy after completion of basic investigations (Figure 2).

Hystero laparoscopic findings were as follows. Uterus was bulky with a normal contour with slightly larger horn on right side. Right tube and ovary were absent. There were omental adhesions on the right side of the fundus, probably due to previous laparotomy and drainage of the hematometra. Left ovary and tube were normal (Figure $3)$.

Hysteroscopy showed left horn of the uterus which was identified by the left cornua. There was a bulge on the right wall of uterus compressing the left cavity. Hence the diagnosis of septate uterus which was atypical, suggestive of Robert's uterus was made. Under laparoscopic guidance, Hysteroscopic resection of atypical septum was done and right horn was entered. Hematometra was drained in to the left horn and cavity made single (Figure 4). Atypical septum was resected.

Subsequent menstrual cycles were uneventful and she was free from dysmenorrhea. Relook hysteroscopy after 4 months showed a single cavity which was slightly asymmetrical and both cornua were seen (Figure 5).

\section{DISCUSSION}

Asymmetric septate uterus (Robert's uterus) is a rare mullerian anomaly. It is a variant of septate uterus class
$\mathrm{V}$ of ASRM classification. ESHRE/ESGE classification explains this anomaly as U2U6C0V0 (Figure 6 and 7).

Robert's uterus was first reported in the year 1969. ${ }^{2}$ Only very few cases have been reported in the literature. ${ }^{3-5}$ This is characterized by a complete septum which is atypical where the septum instead of entering into the cervical canal, it curves towards the lateral wall and forms a non-communicating hemiuterus. Other horn has communication with the normal cervix and vagina. Noncommunicating horn develops haematometra once the menstruation starts. Due to obstruction, patient can develop haematometra, hematosalphinx and even endometrioma on the ipsilateral side. This is what has happened to this patient and she had right salphingo oophorectomy for haematosalphinx and endometrioma. The external morphology of the uterus is often normal except for slight asymmetry at the fundus. When a young teenager reports with progressive dysmenorrhea, authors have to think about mullerian anomaly. Patients usually present in post-menarcheal period with unilateral hematometra causing dysmenorrhea.

The modalities for diagnosis are MRI, CT, USG and hystero laparoscopy. MRI provides excellent tissue characterization helping in differentiating septate from bicornuate uterus and also in diagnosing asymmetric septate uterus. ${ }^{67} 3 \mathrm{D}$ USG/MRI with the help of new ESHRE/ESGE classification system helps to obtain a definite diagnosis of these complex anomalies. High index of suspicion should be there. Management depends upon the situation. Surgery can be done by open or minimally invasive method.

Hysteroscopy is the ideal choice for diagnosis and resection of the atypical septum, as it is minimally invasive. ${ }^{8}$ Uterine volume is also maintained. Surgery can also be done by laparotomy or by laparoscopy, which involves drainage of hematometra and excision of blind non-communicating hemiuterus taking care to maintain the integrity of functional communicating hemiuterus and cervix. ${ }^{9,10}$ In order to avoid inappropriate management, gynecologists should be aware of this rare entity while evaluating cases of severe progressive dysmenorrhoea in young girls. Prompt early diagnosis and surgical correction are essential to avoid future morbidity due to endometriosis. Few cases of successful pregnancies have reported following corrective surgery. ${ }^{11}$ Very rarely pregnancy in non-communicating horn of Robert's uterus can occur due to trans peritoneal migration of sperms. ${ }^{12}$

\section{CONCLUSION}

This case highlights mullerian anomalies have to be considered when young girls present with severe progressive dysmenorrhoea and diagnosis remains a challenge for the clinicians. Gynaecologists should be aware of this rare entity while evaluating such cases. Prompt early diagnosis and surgical correction are 
essential to avoid future morbidity in the form of repeated unnecessary surgeries.

Funding: No funding sources Conflict of interest: None declared

Ethical approval: Not required

\section{REFERENCES}

1. Speroff L. The uterus. Mitchell C, ed. Clinical Gynecologic Endocrinology and Infertility. $7^{\text {th }}$ ed. Philadelphia, Pa: Lippincott Williams and Wilkins; 2005:113.

2. Gupta N, Mittal S, Misra R. A unique congenital mullerian anomaly Robert's uterus. Arch Gynaecol Obstet. 2007;276(6):641-3.

3. Capito C, Sarnacki S. Menstrual retention in a Robert's uterus, J Pediatr Adolesc Gynecol. 2009;22(5):e104-6.

4. Li J, Yu W, Wang M, Feng LM. Hysteroscopic treatment of Robert's uterus with laparoscopy. J Obstet Gynaecol Res. 2015;41(9):1491-4.

5. Sardo AD, Giampaolino P, Scognamiglio M, Varelli C, Nazzaro G, Mansueto G, et al. An exceptional case of complete septate uterus with unilateral cervical aplasia (class U2bC3V0/ESHRE/ESGE classification) and isolated mullerian remnants: combined hysteroscopic and laparoscopic treatment. J Minimal Inv Gynecol. 2016;23(1):16-7.

6. Marcal L, Nothaft MA, Coelho F, Volpato R, Iyer R. Mullerian duct anomalies: MR imaging. Abdom Imag. 2011;36(6):756-64.

7. Bermejo C, Martínez Ten P, Cantarero R, Diaz D, Pérez Pedregosa J, Barrón E. Three-dimensional ultrasound in the diagnosis of mullerian duct anomalies and concordance with magnetic resonance imaging. Ultrasound Obstet Gynecol. 2010;35(5):593-601.

8. Sardeshpande N, Chipalkatti P, Doctor J. Roberts uterus: a rare congenital anomaly. Int $\mathrm{J}$ Reprod Contracept Obstet Gynecol. 2017;6(12):5657-9.

9. Takeuchi H, Sato Y, Shimanuki H, Kikuchi I, Kumakiri J, Kitade M, et al. Accurate reoperative diagnosis and laparoscopic removal of the cavitated non-communicated uterine horn for obstructive Mullerian anomalies. J Obstet Gynaecol Res. 2006;32(1):74-9.

10. Perino A, Chianchiano N, Simonaro C, Cittadini E. Endoscopic management of a case of complete septate uterus with unilateral hematometra. Human Reprod. 1995;10(8):2171-3.

11. Vural M, Yildiz S, Cece H, Camuzcuoglu H. Favourable pregnancy outcome after endometrectomy for a Robert's uterus. J Obstet Gynaecol. 2011;31(7):668-9.

12. Chandra M, Pathak V. Pregnancy in noncommunicating horn of septate uterus. J Obstetric Gynaecol India. 2012;62(Suppl 1):31.

Cite this article as: Devi TR, Devi CA. Robert's uterus: a rare mullerian anomaly mystery unfolded. Int J Reprod Contracept Obstet Gynecol 2020:9:3885-8. 